\title{
The Impact of Systematic Multimedia Instruction on Enhancing Students' Achievement in the Course of Language Evaluation
}

\author{
Zakaria Salameh
}

\begin{abstract}
PowerPoint presentation based on the content of language evaluation was developed by the author which comprised of two parts. Part one presented the knowledge of facts, rules and principles and part two dealt with the skills students should master to write model evaluation tests. The basic principles of systematic instructional design were used along with Gagnes' theory of events of instruction. The aims of this paper is to measure the effect of this systematic multimedia instruction was measured using an achievement test which is divided into two parts. Part one includes 12 multiples choice questions based on the knowledge and the second part includes 16 multiple choice questions based on the skills. The sample of the study consists of 71 students divided into two groups. ANCOVA test was administered to investigate the effect of the program on students' achievement. The results revealed that the systematic multimedia instruction differs significantly between the two groups in knowledge and skills for the sake of the experimental group. The researcher recommended systematic multimedia in other requirements in the English department. it is also recommended using educational technology tools to better enhance students' achievement in this course and other sources
\end{abstract}

Index Terms-Systematic, multimedia instruction, knowledge and skills, events of instruction, educational technology, language evaluation, achievement.

\section{INTRODUCTION}

The use of educational technology has changed every aspect of human life in the world including the EFL classroom. According to Associated Press (2010) there were over 2 billion Internet users, smart phone users, information search engines, and social networking sites. Students at the university level are considered as the generation who depends on technology in many aspects of their lives. Since the beginning of 2000, studies have prevailed that new generations of students are considered as 'Digital Natives' (Prensky, 2001). Prensky described those students as fundamentally different from any students seen before. $\mathrm{He}$ elaborated that students spent their lives surrounded by and using computers, videogames, digital music players, video cameras, mobile phones and many other tools of the modern age. Therefore, because of the new environment, this new generation think and process information totally different than they did in the past [1]. Prensky added that students' brain has also physically changed. Murdock.

Also stated that todays' generation and future generation

Manuscript received October 12, 2015; revised January 18, 2016.

Zakaria Salameh is with Faculty of Arts, University of Hail, Saudi Arabia (e-mail: zakariasalameh@yahoo.com). will never know the world without internet [2].

Nowadays and with the ever increasing use of modern technology in the classroom, the need to use technology means of presenting information in university courses to the students still keeps its stand. The delivery of courses to students may need special scrutiny. Not only educational technology is being used in the classroom, but it also made use of systematic instructional design principles to further improve the teaching and learning process and to achieve the desired objectives. A study conducted by Saragusa (2005) highlighted the significance of instructional analysis, design development, implementation and evaluation in the classroom [3]. Modern technologies of delivering the content sometimes take the form of CDs especially when there is no internet access or slow speed in the internet. Therefore, preprogrammed courses might be delivered to students including evaluation and feedback (Scott \& Judd, 2002) [4].

It is important that decision making takes into consideration the students' experiences of educational technology in order to have implications to improve instructional systematic design (Bani Salameh et al. 2011) [5]. In addition, opportunities present themselves to students to make use of educational technology in the classroom. Starting from using PowerPoint presentations in presenting the material towards using the internet and smart phones to enrich the learning experience, the use of educational technology in the classroom can provide effective ways of stimulating learning (Morris, 2011) [6]. Sprenger (2010) stated that the knowledge and skills delivered to students have changed along with the change among students themselves in using educational technology [7].

Davis (2012) pointed out that digital natives are considered the persons born between 1981 and 2001 while children born after2001 are called millennials. He asserted that today educators must meet the needs of today's generation who are described as savvy students [8].Davis (2012) referred to the "nonconformist" as a new label that describes the learner who develops and designs content using modern technology that has emerged for the learner who creates and designs. He stated that the nonconformist is creative, inquisitive, a leader, and innovative challenging the rules and limits to improve instruction. But it is worth to say that some educational institutions do not allow access to social networking sites which affects the learning process (Sprenger, 2010) [7].

\section{BACKGROUND}

Although university students are high users of computers 
and smart mobiles, there is still a need to publish research on the use of educational technology in the classroom for teaching courses of specific purposes in Saudi Arabia in universities. Therefore, EFL teachers in Saudi Arabia face many challenges. They must be aware of the significance of how and what is being taught to students. Therefore, the challenge is to reach common standards among university students. Hence, the incorporation of educational technology into the EFL classroom is one way to address these challenges and to arrive at a common ground where learning is enhanced. Ward, Moule and Lockyer (2009) stated that there is a need to conduct empirical research to find out if the traditional or the technological educational methods are appropriate for this generation of students [9]. On the other hand, the National Educational Technology Standards (NETS-A and NETS-S) called for teachers to help their students in enhancing learning and creativity, design and develop digital-age learning experiences. (ISTE NETS, 2010).Sprenger (2010) referred to a research which proved that technology changes the way students' brain develops [7].

On the other hand, Xiaoqing Guo et al. (2008) conducted a research on 2000 teachers and found out that no differences exist between digital natives and digital immigrants. They asserted that divide between native and immigrant users might be misleading and they claimed that Prensky's claims were no realistic. In addition, the difference between both groups might not be large [10].

Davis (2012) asserted that "one powerful instructional tool that students respond well to was the use of the multimedia PowerPoint presentation method of instruction." [8] On the other hand, Hansen and Williams (2008) conducted a study on 101 students. 56 students studied through the traditional class and 48 students were in the modern class. The students in the modern group received instruction through multimedia PowerPoint presentations, video clips and textbooks while the traditional class received instruction through lectures and textbook readings. The results of the study revealed that the class with PowerPoint presentation performed better in the exam. In addition, students in the traditional class claimed that they did not buy the textbooks nor completed the assignments. Thus, there were little class discussion and more class time. Students in the modern class, on the other hand, enjoyed discussion of the material and the video presentations. The class students with PowerPoint presentations were more engaged in the learning process [8]. Bartsch and Cobern (2003) conducted two studies on the impact of overhead transparencies, basic PowerPoint and enhanced PowerPoint on learning. The study revealed that students preferred the Multimedia PowerPoint presentations over the use of overhead transparencies. They claimed that they learned more with PowerPoint presentations. They also found out that unrelated graphics negatively affect learning [11].

Apperson et al. (2004) conducted a study at a small university in the Atlantic region on measuring the effect of using multimedia PowerPoint presentation on enhancing students' achievement. The sample of the study consisted of 104 students in the chalk and lecture method and 95 students in the PowerPoint classes. The result of the study showed that Students' perception and attitudes and skills were in favor of the experimental group. Students in the experimental group mentioned that the class was more organized and it enhanced focus in the class. They also stated that the understanding of the course content was enhanced. [12]

Sugahara and Boland (2006) stated that since the 1990s it was thought that the use of multimedia presentation affects learning positively. But they claimed that it may not enhance students' grades but that students prefer the PowerPoint method. In their study on 189 undergraduate students they emphasized that students' preference of PowerPoint presentation does not contribute to students' achievement [13]. However, Deal (2005) conducted two studies and found out that knowledge and skills retention is enhanced through using visual presentation in the PowerPoint. In addition, visual aids improve communication and effectiveness [14].

Jing (2009) conducted a study on a group of pre-service teachers who were supposed to be professional in the use of technology in the classroom. Jing found out that technology proficiency among those teachers was limited with regard to scope and the use of activities through the instructional technology in enhancing students' achievement [15].

On the other hand, instructional design is the systematic process of translating general principles of learning and instruction into plans for instructional materials and learning in order to solve problems (Morrison \& Ross, 1996) [16]. A major approach followed in instructional systematic design is Dick and Carey model (2001) [17]. The purpose of using this approach in this study is to maintain knowledge and skills and prevent knowledge decay. Dick and Carey model includes major components which can be summarized through analysis, strategy development and evaluation. The Dick and Carey model, which is adopted in this study, represents a systematic approach to curriculum and program design (Morrison \& Ross, 1996) [16]. According to Gagne et al (1992), lesson planning must go through the following steps: First, the objective of the lesson should be clarified, considering that some lessons might include more than one objective. Second, the events of instruction should be presented without necessarily referring to all the events in one lesson or to be presented in order [18]. The third is choosing the media materials and activities that suit the objective. These materials can be used if available or new material is required. Dick and Carey (2001) model of systematic instructional design is used in this study which conforms to the approach proposed by Gagne.

Green (2008) conducted a study on systematic design to enhance situation awareness. He followed Gagne's domains of learning. The results of the study showed that knowledge and skills improved significantly [16].

The use of systematic instructional design in this study along with Multimedia PowerPoint presentation is essential to be incorporated in the class room to enhance students' achievement (Bani Salameh, 2013) [5]. Hence, the aim of this study is to investigate the effect of using systematic multimedia PowerPoint presentation to enhance students' knowledge and skills among university students in the course of Language Evaluation in the English department at the University of Hail. Thus, the research questions are:

1) Is there a difference between the mean scores of the experimental group and control group on knowledge of Language Evaluation that can be attributed to the use of 
the systematic multimedia instruction.

2) Is there a difference between the mean scores of the experimental group and the control group on mastering the skills of Language Evaluation that can be attributed to the use of the systematic multimedia instrcuction.

\section{PRoBlem STATEMENT}

Tapscott (2009) stated that the use of educational technology has changed the way new generations of students learn. The availability and use of technology differs from one educational system to another. Therefore, lack of use of technology might affect students' achievement and could present drawbacks of not satisfying the educational needs and desired outcomes of todays' digital native students [20].

According to the researcher experience, it has been noticed that achievement among students studying the course of Language Evaluation has been low over three semesters. The main characteristics of the previous experiences are that no systematic PowerPoint presentation was used to teach students. Since the beginning of the second semester 2014, new instructions have been imposed that all English language instructors must use PowerPoint presentation in teaching their students. The researcher in this study used systematic multimedia PowerPoint instruction in the course of Language Evaluation in the experimental group and the traditional group were taught through the traditional approach of instruction without making use of educational technology. The objective of this method of instruction was to measure students' achievement in the course of 'Language Evaluation.'

\section{Methodology}

\section{A. Particpants}

The population of the study was 1200 students studying English language at the English department in the University of Hail in the year 2014. The sample of the study included 71 students chosen randomly and divided into two groups, the experimental group and the control group (Cohen, 2005) [21]. They are all at the fourth level of their university study and they are all between the age of 21 and 22 years old.

\section{B. Research Design}

The subjects of the study consisted of two groups: one control group and one experimental group. It comprised 71 students chosen randomly. The control group consisted of 34 students and the experimental group consisted of 37 students. The study is a quasi-experimental. The independent variable is the instructional program, which is divided into two levels, knowledge, the first part of the course material and skills, the second part of the course material. The dependent variable is divided into two levels, (A) recall of knowledge and(B) recall of skills. The systematic multimedia PowerPoint instruction was developed using Gagne's Nine Events of Instruction (Gagne, 1992) and Dick and Carey model of systematic instructional design (2001) and are reflected in the content and the structure of the systematic PowerPoint presentation
[17].

\section{Instrument}

The researcher of this article developed the systematic multimedia PowerPoint instruction. The content of the presentation was evaluated by five instructors from the English department and five instructors from the educational technology department who assessed the appropriateness of the program properties. An achievement test was developed based on the knowledge and skills in the course of language evaluation. This test included two parts. The first part consisted of 12 multiple-choice questions (measurings knowledge), and part two consisted of 16 multiple-choice questions (measuring skills).

\section{Procedure of the Multimedia PowerPoint Instruction}

The first page of the PowerPoint presentation is the home page. It provides students basic knowledge about the content of the course of Language Evaluation. The instructor explained the contents of part one which included knowledge and part two which included skills. The flow of the content followed Gagne' nine events of instruction which is based on the following principles:

1) Gaining attention

2) Informing learners of objectives

3) Stimulating recall of prior learning

4) Presenting the content

5) Providing learning guidance

6) Eliciting performance

7) Providing feedback

8) Assessing performance

9) Enhancing retention and transfer

The control group studied the course through the traditional lecture approach using the whiteboard and the second group studied the course though using the systematic multimedia PowerPoint instruction available in the class room.

\section{E. Instructional Material}

The instructional material is based on the syllabus of Language Evaluation taught in the English department at the University of Hail. The content material is based on ten lessons in light of the course description. The first six lessons were based on knowledge of the basic concepts in language evaluation. The second four lessons were based on skills required to construct tests in grammar, listening, speaking, reading and writing. Gagne's theory of hierarchical learning was used in teaching the twelve lessons, particularly the events of instruction [15].

\section{F. Instrument Validity and Reliability}

The achievement test was validated by five instructors from the English department who confirmed that the test was appropriate and that it was easy in form and clear in terms of what was required. The test reliability was verified through the test-retest method on a group of 30 students (not from the actual study group), chosen randomly from the population of the study. The period between the two tests was 2 weeks. The Pearson correlation coefficient computed for the test was 0.82 , which was considered to be suitable for the purpose of this study (Cohen, 2005) [19]. 


\section{RESUlTS OF THE STUDY}

\section{A. Data Analysis}

ANCOVA test was conducted in order to investigate the existence of the differences through comparing between the mean scores of the two groups. The independent variable in this study was the systematic multimedia PowerPoint instruction and the dependent variable is divided into two parts, knowledge and skills. The significance level is set at ( $p$ $=0.05)$.

\section{B. Questions of the Study Are the Following}

1) Is there a difference between the mean scores of the experimental group and control group on recall knowledge of Language Evaluation that can be attributed to the use of the systematic multimedia PowerPoint instruction.

2) Is there a difference between the mean scores of the experimental group and the control group on mastering the skills of Language Evaluation that can be attributed to the use of the systematic multimedia PowerPoint instruction.

The study aimed at investigating the effectiveness of the teaching method on students' knowledge and skills in the course of language evaluation. The control group consisted of 34 students and the experimental group consisted of 37 students (Table I).

\begin{tabular}{|c|c|c|c|}
\hline & & Value Label & $\mathrm{N}$ \\
\hline T.M & $\begin{array}{l}1.00 \\
2.00\end{array}$ & $\begin{array}{l}\text { Conventional teaching } \\
\text { method } \\
\text { PowerPoint method }\end{array}$ & $\begin{array}{l}34 \\
37\end{array}$ \\
\hline
\end{tabular}

Table II gives the Means, Standard deviation for Knowledge. The Mean scores of Knowledge in the conventional method is $X=10.18$ with s.d $=2.48$, while the mean scores of Knowledge for the multimedia PowerPoint instruction method is $X=17$ with s.d $=1.53$. The mean total score is $X=13.7$ with s.d $=3.95$. For Knowledge the Mean score for the PowerPoint presentation teaching method showed an increase of 6.82 over the traditional teaching method.

TABLE II: MEAN, STANDARD DEVIATION FOR KNOWLEDGE

\begin{tabular}{|l|l|l|l|}
\hline T.M & Mean & Std. Deviation & N \\
\hline Traditional teaching method & 10.1765 & 2.47987 & 34 \\
PowerPoint method & 16.9189 & 1.53439 & 37 \\
Total & 13.6901 & 3.95182 & 71 \\
\hline
\end{tabular}

To verify the Mean differences the researcher conducted ANCOVA test. Table III shows the results of the ANCOVA test where $\mathrm{F}=(1.68)=180.5$ at $p=.000$. As $p<0.05$, there are significant differences between the two groups with regard to Knowledge for the sake of the PowerPoint group.

Table IV gives the Means, Standard deviation for skills. The Mean scores of skills in the traditional method is $X=$ 20.18 with s.d $=2.43$, while the mean score of skills for the PowerPoint instruction method is $X=23.90$ with s.d $=2.70$. The mean total score is $X=22.10$ with s.d $=3.15$. For skills the Mean score for the PowerPoint presentation method showed an increase of 3.72 over the conventional teaching method.

TABLE III: ANCOVA TEST FOR THE DIFFERENCE BETWEEN MEANS OF STUDENTS' SCORES ON KNOWLEDGE

\begin{tabular}{|l|l|l|l|l|l|}
\hline & $\begin{array}{l}\text { Type III } \\
\text { Sum of } \\
\text { Squares }\end{array}$ & Df & $\begin{array}{l}\text { Mean } \\
\text { Square }\end{array}$ & F & Sig. \\
\hline Corrected Model & $815.808(\mathrm{a})$ & 2 & 407.904 & 100.000 & .000 \\
Intercept & 556.519 & 1 & 556.519 & 136.434 & .000 \\
pretest_knowledge & 10.323 & 1 & 10.323 & 2.531 & .116 \\
T.M & 736.354 & 1 & 736.354 & 180.521 & .000 \\
Error & 277.375 & 68 & 4.079 & & \\
Total & 14400.000 & 71 & & & \\
Corrected Total & 1093.183 & 70 & & & \\
\hline
\end{tabular}

TABLE IV: MEANS, STANDARD DEVIATION FOR SKILLS

\begin{tabular}{|l|l|l|l|}
\hline T.M & Mean & $\begin{array}{l}\text { Std. } \\
\text { Deviation }\end{array}$ & $\mathrm{N}$ \\
\hline $\begin{array}{l}\text { Conventional } \\
\text { teaching method }\end{array}$ & 20.1765 & 2.43050 & 34 \\
$\begin{array}{l}\text { PowerPoint } \\
\text { method }\end{array}$ & 23.8649 & 2.68909 & 37 \\
Total & 22.0986 & 3.15393 & 71 \\
\hline
\end{tabular}

To verify the Mean differences the researcher conducted ANCOVA test. Table $\mathrm{V}$ shows the results of the ANCOVA test where $\mathrm{F}=(1.68)=32.52$ at $p=.000$. As $p<0.05$, there are significant differences between the two groups with regard to skills for the sake of the PowerPoint presentation group.

TABLE V: ANCOVA TEST FOR THE DIFFERENCE BETWEEN MEANS OF

\begin{tabular}{|l|l|l|l|l|l|}
\hline & $\begin{array}{l}\text { Type III } \\
\text { Sum of } \\
\text { Squares }\end{array}$ & df & $\begin{array}{l}\text { Mean } \\
\text { Square }\end{array}$ & F & Sig. \\
\hline $\begin{array}{l}\text { Source } \\
\text { Modected } \\
\text { Intercept } \\
\text { pretest_pro_ } \\
\text { solving } \\
\text { T.M }\end{array}$ & $246.382(\mathrm{a})$ & 2 & 123.191 & 18.619 & .000 \\
$\begin{array}{l}\text { Error } \\
\text { Total }\end{array}$ & 21382.531 & 1 & 1382.531 & 208.949 & .000 \\
Corrected & 4438 & 1 & 5.338 & .807 & .372 \\
Total & 6936.928 & 1 & 215.055 & 32.502 & .000 \\
\hline
\end{tabular}

\section{DISCUSSION}

The aim of this research was to measure the effect of the systematic multimedia PowerPoint instruction on improving students' achievement in knowledge and skills in the course of Language Evaluation in the English department at the University of Hail in the second semester 2014. Students are at the age of 21 and 22 years and are considered digital natives according to Davis (2012) [8].

The proceeding of this research conforms with the principles by Ward, Moule \& Lockyer (2009) and Cilesiz (2009) who emphasized the importance of conducting empirical research to find differences between traditional and using technology in education. But the case here does not allow access to social networking (Sprenger, 2010). Therefore, the researcher used offline systematic multimedia PowerPoint instruction [7]. 
The results of analysis showed that the ANCOVA test $\mathrm{F}=$ $(1.68)=180.5$ at $p=.000$. As $p<0.05$, there are significant differences between the two groups with regard to Knowledge for the sake of the PowerPoint presentation group.

The reason behind the significant differences in knowledge might be due to the use of systematic multimedia in the PowerPoint instruction which helped students recall the knowledge needed. The results of this study are in line with the points of view of Mario \& Obrien (2001), Tahboub (2003), and Al Omary (2005). All these studies assured that using PowerPoint instruction has a significant effect in improving students' achievement compared with traditional methods. This might be due to the fact that computer based programs are appropriate aids that enhances students' achievement through the use of systematic multimedia which motivates students and enhances their achievement. On the other hand, this study shows conformity with the findings of Pegrell (1985) and Hutchinson \& Waters (1987) whose results provided evidence on the positive effect of progress on English foreign language learners (EFL) achievement including the listening and the reading skills. It was also in line with the results by Davis (2012) [8], Sugahara\& Boland (2006), Hansen \& Williams (2008) [22], Bartsch \& Cobern (2003) in increasing achievement through systematic design. The use of systematic instructional design in this study along with PowerPoint instruction is essential to be incorporated in the class room to enhance students' achievement (Apperson et al. 2004) [12] and Bani Salameh (2013) [5].

On the other hand, the study found out that the results of ANCOVA test showed that $\mathrm{F}=(1.68)=32.5$ at $p=.000$. As $p<0.05$, there are significant differences between the two groups with regard to Skills for the sake of the PowerPoint instruction group.

This result is in line with (NETS-A and NETS-S) which called for teachers to help their students in enhancing learning and creativity, design and develop digital-age learning experiences (ISTE NETS, 2010). Sprenger (2010) also referred to a research which proved that technology changes the way students' brain develops [7].Moreover, Apperson et al (2004) found out that using PowerPoint instruction was better in perception and skills [12] and Deal (2005) conducted two studies and found out that knowledge and skills retention is enhanced through using visual presentation in the PowerPoint [14].In addition, Morris (2011) found out that systematic technology instruction stimulates learning [12].

In light of using instructional systematic design (ISD), the results were also in line with Scott and Judd (2002) who stressed the importance of programmed courses [20]. Bani Salameh et al. (2011) [5] and Saragusa (2005) also highlighted the significance of instructional analysis, design development, implementation and evaluation in the classroom [13]. Morrison \& Ross (1996) and Dick and Carey (2001) proved that using instructional design improves learning.

In addition to the above mentioned, in this study the researcher developed the PowerPoint presentation program through the use of Gagne's theory of hierarchical learning with the events of instruction and Dick and Carey (2001) model of instructional systematic design (ISD). These events of instruction must have enhanced skills among students (Bani Salameh et al. 2010).This conforms with Green (2008) who found the positive effect of using Gagne's domains of learning through hypermedia in improving mastery of skills [18].

Although the above discussion supports the use of systematic multimedia PowerPoint instruction, other studies such as the study by Jing (2009) on a group of pre-service teachers who were supposed to be professional in the use of technology in the classroom found out that technology proficiency among those teachers was limited and did not contribute to enhancing students' achievement [15].

\section{RECOMMENDATIONS AND IMPLICATIONS FOR FUTURE RESEARCH}

In conclusion, this research shed light on the importance of using educational technology particularly the use of systematic multimedia PowerPoint instruction on students' achievement in the course of Language Evaluation in the English department at the University of Hail. The use of systematic instruction in teaching English language requirements opens broad avenues towards improving knowledge and skills using the proper theory and systematic principles of instructional design.

This research employed and investigated the use of PowerPoint presentation on one requirement from the course plan of the English language department. Further research is required using other requirements in a course plan of 128 credit hours.

Gagne's theory and events of instruction with systematic instructional design should be used for the rest of the requirements. In addition, other instructional theories might be used to investigate the elements which might improve students' achievement. In addition, instructional packages and CDs should be provided to students to use them at their own pace.

In is worth mentioning here that no qualitative research was employed in this research and it would be interesting to use instruments like interviews and observations in future researches.

Finally, there is a need to investigate the use of other educational technologies in the English department at the University of Hail, such as using more interactive multimedia and simulations in other requirements like in Linguistics and Literature. In addition, the objective of improving students' attitudes in such a research and towards the use of social networking needs to be studied thoroughly.

The Conclusion that can be drawn from this research is that systematic multimedia PowerPoint instruction based on Gagne's events of instruction was significant in improving students achievement in knowledge and skills. The high mean scores in the achievement test were due to the use of the PowerPoint presentation program.

The researcher recommended using educational technology tools to better enhance students' achievement in this course and other sources.

\section{ACKNOWLEDGMENT}

I would like to thank Hail University for supporting this research. 


\section{REFERENCES}

[1] M. Prensky, "Digital natives, digital immigrants," On the Horizon, vol. 9, no. 5, 2001.

[2] R. Murdoch, "Speech by Rupert Murdoch to the American Society of Newspaper Editors," American Society of Newspaper Editors, 2005.

[3] L. Saragusa, "Identification of effective instructional design principles and learning strategies for students studying in Web-based learning environments in higher education," PhD thesis, Curtin University of Technology, Perth, 2005.

[4] N. Scott and K. Judd, "Efficient continuous online assessment of large classes: Continuous diagnostic assessment in engineering \& mathematics subjects," 2004.

[5] Z. B. Salameh et al., "Design and development of systematic interactive multimedia instruction on safety topics for flight attendants," in Proc. the $5^{\text {th }}$ International Conference on e-Learning, 2010.

[6] N. Morris, "Using Technology in the EFL classroom in Saudi Arabia," Master Thesis, SIT Graduate Institute, 2011.

[7] M. Sprenger, Brain-Based Teaching: In the Digital Age, Alexandra: ASCD, 2010.

[8] C. Davis, "The effects of technology instruction on the academic achievement of fifth grade students," PhD, Libert University, 2012.

[9] R. Ward, P. Moule, and L. Lockyer, "Adoption of Web 2.0 technologies in education for health professionals in the UK: Where are we and why?" Electronic Journal of e-Learning, vol. 7, no. 2, 165-172, 2009.

[10] S. Petrina et al., "Digital natives, digital immigrants: An analysis of age and ICT competency in teacher education," Journal of Educational Computing Research, vol. 38, pp. 235-254, 2008.

[11] R. Bartsch and K. Cobern, "Effectiveness of PowerPoint presentations in lectures," Computers \& Education, vol. 41, pp. 77-87, 2003.

[12] J. Apperson, E. Laws, and J. Scepansky, "The impact of presentation graphics on students' experience in the classroom," Computers \& Education, vol. 47, pp. 116-126, 2004.
[13] S. Sugahara and G. Boland, "The Effectiveness of PowerPoint Presentations in the Accounting classroom," Accounting Education, vol. 15 , no. 4, pp. 391-403, 2006.

[14] W. Deal, "Resources in technology," Technology Teacher, vol. 64, no. 8, pp. 12-16, 2005.

[15] L. Jing, "Digital natives as pre-service teachers: What technology preparation is needed?" Journal of Computing in Teacher Education, vol. 25, no. 3, pp. 87-97, 2009.

[16] K. Morrison and G. Ross, Designing Effective Instruction, Upper Saddle River, NJ: Prentice Hall, 1996.

[17] W. Dick and L. Carey, The Systematic Design of Instruction, New York, NY: Harper Collins Publishers Inc, 2001.

[18] R. Gagne, L. Briggs, and W. Wager, Principles of Instructional Design, Fort Worth, TX: HBJ College Publishers, 1992.

[19] R. Green, Cognitive Task Analysis for Life Science Automation Training Program Design, p. 187, 2008.

[20] D. Tapscott, "Grown up digital: How the net generation is changing your world," Journal of Faculty of Education, New York, vol. 5, no. 1, pp. 156-187, 2009.

[21] L. Cohen, L. Manion, and K. Morrison, Research Methods in Education, Taylor \& Francis e-Library, 2005.

[22] C. Hansen and M. Williams, "Comparison of cross-cultural course changes: From traditional lecture course to contemporary course with biblio-learning, video learning and experimental exercise," Journal of Instructional Psychology, vol. 30, no. 3, pp. 197-206, 2008.

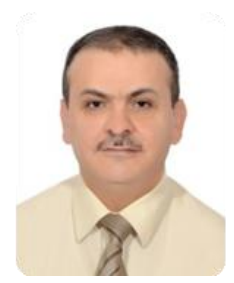

Zakariya A. Salameh was born in Jordan in 1971. He finished his $\mathrm{PhD}$ in educational technology in 2012, granted USM fellowship during PhD study and was awarded the certificate of excellence in writing research papers by USM. Currently he is working as an assistant professor in the English Department in the Faculty of Art at Hail University. 